\title{
Cerebral Hemodynamic Response to Unpleasant Odors in the Preterm Newborn Measured by Near-Infrared Spectroscopy
}

\author{
MARCO BARTOCCI, JAN WINBERG, GESA PAPENDIECK, TERESA MUSTICA, \\ GIOVANNI SERRA, AND HUGO LAGERCRANTZ
}

Department of Paediatrics, Neonatal Intensive Care, University of Genoa, Gaslini Institute, Genoa, Italy [M.B., G.P., T.M., G.S.]; Department of Woman and Child Health, Neonatal Research Unit, Karolinska Institute, Stockholm, Sweden [M.B., J.W., H.L.]

ABSTRACT

\begin{abstract}
Newborn infants in intensive care units are exposed to several unfamiliar smells, mostly related to the nosocomial environment. How the preterm baby perceives these olfactory stimulations remains unclear. Near-infrared spectroscopy can be performed noninvasively above the olfactory cortex to monitor changes of cerebral blood flow as an indicator of cortical activation. The aim of this study was to explore by near-infrared spectroscopy how odorous substances routinely used in the neonatal intensive care unit influence bilateral cortical hemodynamics in the olfactory region of the brains of preterm infants. Specifically, a detergent (Neomidil) and an adhesive remover (Remove) have been tested. Twenty preterm neonates of gestational age 30-37 wk (mean $33.7 \pm 2.3 \mathrm{SD}$ ) and postconceptional age $32-37.3 \mathrm{wk}$ (mean 35.5 $\pm 2.75 \mathrm{SD}$ ) were monitored by near-infrared spectroscopy. Two optode pairs were placed above the anterior orbitofrontal gyri, which is involved in olfactory processing, on each side of the skull. Fifteen babies were exposed to the smell of a disinfectant and five babies to that of a detergent, both applied to small cotton pads. Changes of oxygenated $\mathrm{Hb}$ and deoxygenated $\mathrm{Hb}$ were recorded before, during, and after a 10 -s stimulus. In 17 out of 20
\end{abstract}

babies, there was a decrease in oxygenated $\mathrm{Hb}$ and total $\mathrm{Hb}$ after the exposure to the substances. The decrease was significantly greater in the right side than in the left side. This change was different from that observed in our previous study after exposure to colostrum and the pleasant smell of vanilla, which elicited an increase in blood oxygenation in the same region. The biologic significance of this finding is unknown. We conclude that cortical hemodynamic modifications occur in the preterm newborn after exposure to preparations commonly used in the neonatal intensive care unit. A lateralization seems to occur in processing unpleasant olfactory cues. (Pediatr Res 50: 324-330, 2001)
Abbreviations:
NICU, neonatal intensive care unit
NIRS, near-infrared spectroscopy
$\left[\begin{array}{ll}\mathbf{H b} & \mathrm{O}_{2}\end{array}\right]$, oxygenated $\mathrm{Hb}$
[Hb $\mathrm{H}]$, deoxygenated $\mathrm{Hb}$
[Hb tot], total $\mathrm{Hb}\left(\left[\mathrm{Hb} \mathrm{O}_{2}\right]+[\mathrm{Hb} \mathrm{H}]\right)$
r-CBF, regional cerebral blood flow

The newborn infant is exposed to a multitude of nonphysiologic environmental stimuli, which are perceived, processed, and elaborated in the form of different responses, both physiologic and behavioral. Some of these stimuli have been shown

Received November 30, 2000; accepted May 22, 2001.

Correspondence: Marco Bartocci, M.D., Karolinska Institute, Neonatal Research Unit, Astrid Lindgren's Children Hospital, Q2:07, Karolinska Hospital, 17176 Stockholm, Sweden; e-mail: marco.bartocci@kbh.ki.se

Supported by the Frimurare Foundation, Stockholm, Sällskapet Barnavård Foundation, Förstamajblommans Riksförbund, Göteborg, and Samariten Foundation, Stockholm.

Preliminary results of this study were presented at the Fifth International Conference on Functional Mapping of the Human Brain, June 22-26, 1999, Düsseldorf, Germany, and at the Annual Meeting of the American Pediatric Society/The Society for Pediatric Research, May 12-16, 2000, Boston, MA, U.S.A. to affect the growth, development, and survival of the neonate, especially the premature infant treated in the NICU (1-5). Most studies have focused on responses to visual $(3,5,6)$, auditory $(3,5,7,8)$, and tactile stimulation $(1,3,5)$. However, there is little information about the responses to a large variety of pungent and artificial odorous compounds (i.e. disinfectants, detergents, adhesive removers) to which the premature baby is exposed. In a recent study by our group, we found that unfamiliar, but likely pleasant, olfactory cues such as colostrum and vanilla can elicit a hemodynamic cortical response in healthy newborns. This suggests olfactory processing (9).

The olfactory system is well structured from 32-34 wk of gestation and distinct behavioral responses to olfactory stimuli 
have been observed from 32 wk of gestation (10). Other components of the olfactory system, such as trigeminal and accessory subsystems, seem to be responsive at $30 \mathrm{wk}$ of gestation or even earlier.

Cortical processing in preterm infants in response to olfactory stimuli, particularly when these are unfamiliar and likely unpleasant, is still unclear. The main aim of the present study was to assess using NIRS the hemodynamic changes in the olfactory cortex when premature infants were exposed to two, likely unpleasant, substances commonly used in the NICU.

NIRS is a noninvasive technique capable of monitoring changes in blood concentration of chromophores such as $[\mathrm{Hb}$ $\left.\mathrm{O}_{2}\right]$ and $[\mathrm{Hb} \mathrm{H}]$. Recently, NIRS has been used to study functional activation of various cortical regions of the human brain. The basic assumption is that changes in $\left[\mathrm{Hb} \mathrm{O}_{2}\right]$ and $[\mathrm{Hb}$ $\mathrm{H}]$ concentration are strictly related to changes in blood flow, which in turn are coupled to neuronal activity (11-15). Although the majority of studies performed thus far have used adult subjects, this method has also been used on newborns during the last 3 y (6-9). The relationship between hemodynamic changes and neuronal activation in the illuminated cortical area has been studied under various conditions, such as in response to visual $(6,12,16-19)$, acoustic $(7,8)$, and olfactory (9) stimuli.

\section{MATERIAL AND METHODS}

\section{Study Group}

Twenty preterm newborn infants with a mean gestational age (GA) of $33.7 \mathrm{wk}$ (range, 30-37), a mean postconceptional age (PC) of $35.5 \mathrm{wk}$ (range, 32-37.3), and a mean postnatal age (PN) of $12.5 \mathrm{~d}$ (range, $0.75-35$ ) at testing were studied. Of these, 15 were admitted to the NICU, Department of Pediatrics, Gaslini Institute, University of Genoa (mean GA, $33.1 \mathrm{wk}$; range, 30-36 wk), and 5 to the NICU, Astrid Lindgren's Children's Hospital, Karolinska Institute, Stockholm (mean GA, $35.4 \mathrm{wk}$; range, 33-37).

At the time of the experiment, all babies were in stable condition and breathing spontaneously without any need of oxygen supplementation or infusion. All were fed with mother's milk, given by bottle, and at least $2 \mathrm{~h}$ had passed since their last meal (mean, $2.9 \mathrm{~h}$; range, $2-4 \mathrm{~h}$; SD 0.47). Cranial ultrasound scans were normal in all babies.

The babies were studied in their incubator while lying in the supine position in a quiet, awake state (20). The incubator temperature was kept constant around $29-30^{\circ} \mathrm{C}$, the light was $\mathrm{dim}$, and the noise level was reduced as much as possible. The duration between the last handling and the experimental time was at least $30 \mathrm{~min}$. Parents were allowed to be present at the experiment session, but they were asked not to touch or talk to their baby during the test.

The local ethics committees in both Stockholm and Genoa approved the study and parental informed consent was obtained.

\section{Heart Rate Respiration Rate and Arterial Oxygen Saturation Data}

Heart rate (HR) respiration rate (RR), and arterial oxygen saturation $\left(\mathrm{SaO}_{2}\right)$ were simultaneously registered during the experiment using an HP monitoring system including pulse oximetry (Hewlett-Packard, Boeblingen, Germany ). HR, RR, and $\mathrm{SaO}_{2}$ data were transferred through an RS232 interface card to a personal computer at a sampling rate of $1 \mathrm{~Hz}$. Average values for the baseline period, as well as at 10,20, and $30 \mathrm{~s}$ after the stimulus, were calculated for each infant. Stepwise regression analysis (ANOVA-MANOVA) and Newman-Keuls posthoc comparisons were used to compare the different values throughout the experiment. Differences in the male and female groups were analyzed using a $t$ test for independent samples.

\section{Odors}

In Genoa, we tested on 15 babies the smell of a disinfectant solution (Neomidil, Pharmec, Rome, Italy) routinely used in our NICU. This solution is composed of benzyl chlorate $(0.25 \%)$, ethyl alcohol $(66.29 \%)$, and excipients such as lemon oil, acetone, isopropyl alcohol, camphor, and purified water.

In Stockholm, we monitored five neonates during exposure to the smell of a detergent frequently used to remove tape from an infant's skin (Remove, Smith \& Nephew; Mölndal, Sweden). This substance contains dipropylene glycol methyl ether (45-55\%), water, and mineral essences.

The study population was originally composed of 30 babies. However, the recordings could not be evaluated in 10 babies because of movement artifacts on the NIRS trace. Most of these artifacts were the result of head movements, which were often related to the baby's reaction to the smell of the tested substance. Of these 10 babies, 3 ( 2 females and 1 male) were admitted to Genoa Hospital and 7 (4 females and 3 males) to Karolinska Hospital. GA and age at the time of the experiment were similar to those of the study group.

A $2 \times 2-\mathrm{cm}$ pad was soaked in $1.5 \mathrm{~mL}$ of the testing compound (the remover was presoaked in its commercial package) and thus presented to the infants at a distance of about $2 \mathrm{~cm}$ from the nostrils for $10 \mathrm{~s}$. The pad was held by the researcher at the far end so that the fingers were approximately $4 \mathrm{~cm}$ from the infant's nostrils. The cotton pad was moved slowly from left to right and vice versa, but essentially remained in front of both nostrils for the entire 10-s duration. Care was taken not to touch the skin of the baby. The infant was not exposed to the tested substance during the hour before the experiment.

Responses to the stimuli were compared with those observed in our previous study (9) after exposure to colostrum as a biologically meaningful odor, vanilla (vanilla essence, 4-hydroxy-3-methoxy-benzaldehyde, The Body Shop, West Sussex, U.K.) as a likely pleasant odor, and water as a negative control.

\section{Panel Evaluation of the Smell}

The intensity and hedonic value of Neomidil, Remove, and the three control fluids (distilled water, colostrum, and vanilla), 
were evaluated by 12 adults ( 6 males and 6 females). For rating of intensity, we used a $20-\mathrm{cm}$ long visual analogue scale. For rating of pleasantness, the middle point of the $20-\mathrm{cm}$ scale was defined as neutral, the left extreme $(-10 \mathrm{~cm})$ as maximal unpleasantness and the right extreme $(+10 \mathrm{~cm})$ as maximal pleasantness. The gradation expressed by the panelists as measured in centimeters was analyzed using ANOVA and posthoc testing.

Water and colostrum were presented first, followed by vanilla, disinfectant, and detergent. This sequence was chosen to avoid stronger odors affecting the perception of more faint odors.

A cotton swab soaked in the solution was moved under the nostrils at a distance of $2 \mathrm{~cm}$ for $10 \mathrm{~s}$. All the panelists were exposed to the same sample of colostrum. This sample was taken from a mother $2 \mathrm{~d}$ after she gave birth to a 37-wkgestation baby.

\section{NIRS Settings}

Changes in $\left[\mathrm{Hb} \mathrm{O}_{2}\right],[\mathrm{Hb} \mathrm{H}]$, and $[\mathrm{Hb}$ tot] were monitored using a double-channel NIRS device (NIRO 300, Hamamatsu Photonics, Hamamatsu, Japan). This technique allows noninvasive monitoring of concentration changes in natural chromophores, such as $\mathrm{Hb}$ in oxygenated and deoxygenated state, as well as cytochrome $c$ oxydase - the last enzyme of the respiratory mitochondrial chain - in the redox state of the. Light in the near-infrared spectrum between 700 and $1000 \mathrm{~nm}$ can penetrate biologic tissues, including bone. Based upon the modified Beer-Lambert law applied to light attenuation changes through the illuminated tissue, it is possible to calculate changes in chromophore concentration. The basic principles of NIRS and its reliability in studying newborn infants have been described in detail (21-25).

In brief, NIRO 300 is provided with four pulsed-laser diodes producing light at different wavelengths $(775,810,850$, and $910 \mathrm{~nm}$ ). Each diode has a pulse frequency of approximately 2 $\mathrm{kHz}$, and each pulse lasts about $100 \mathrm{nsec}$. Near-infrared light is provided by an emission optode $[8 \mathrm{~mm}(\varnothing) \times 4 \mathrm{~mm}(\mathrm{H})]$ and detected by a recipient optode $[20 \mathrm{~mm}(\varnothing) \times 8 \mathrm{~mm}(\mathrm{H})]$ where $\varnothing=$ diameter and $\mathrm{H}=$ height. The optodes were placed in a special black semirigid rubber holder with an interoptode distance of $4 \mathrm{~cm}$. Each pair of emission and recipient optodes was positioned symmetrically on each side of the skull. The emitting optode was placed $2 \mathrm{~cm}$ above the midpoint of the line connecting the external angle of the eye to the homolateral tragus (slightly anterior to the $\mathrm{T} 3$ position according to the international EEG 10-20 system) (Fig. 1). This location likely enabled the illumination of the orbitofrontal gyrus of the frontal lobe. We established a differential path-length factor (DPF) of 4.2 (26). Sampling was performed every second.

\section{Smell Stimulus and Data Storing}

After placing NIRS optodes on the head, a starting period of about 2 min was passed, during which the signal was adjusted and stabilized. Next, a 30 -s period of NIRS baseline was defined. The small pad soaked in the substance to be tested was then moved slowly from one nostril to the other for $10 \mathrm{~s}$ at a

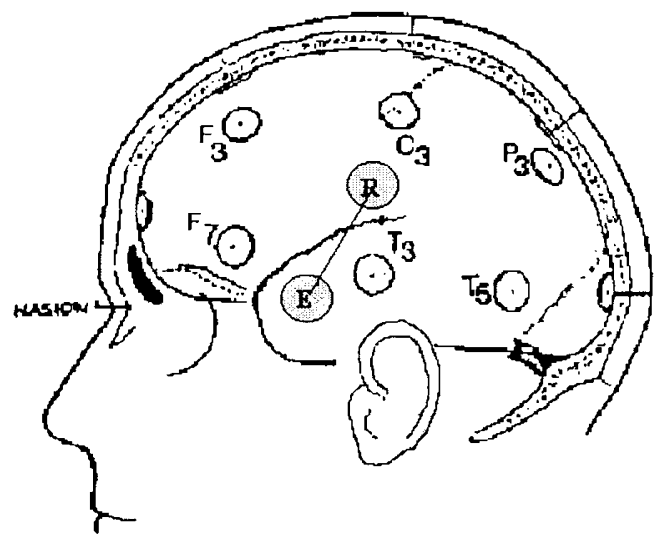

Figure 1. Optode position. The sketch shows how the optodes (gray circles; $R$, receiver; $E$, emitter) were positioned on the skull of the baby to illuminate the olfactory region. The international standard EEG electrode position has been used as a reference system (white circles) for positioning the optodes. Each pair of optodes was placed symmetrically on both sides of the head. The distance between the $\mathrm{E}$ and $\mathrm{R}$ was $4 \mathrm{~cm}$. As an anatomical reference, the line connecting the lateral corner of the eye to the tragus was taken. The emitting probe was located approximately $2 \mathrm{~cm}( \pm 0.5 \mathrm{~cm})$ above the midpoint of this line.

distance of approximately $2 \mathrm{~cm}$. Through an RS232 A/D board, NIRS data were transferred online to a personal computer. The beginning and end of each registration period were marked on the NIRS curve. The initiation of the 10-s smell exposure period was also marked. Changes in $\left[\mathrm{Hb} \mathrm{O}_{2}\right]$ and $[\mathrm{Hb} \mathrm{H}]$ were analyzed and $[\mathrm{Hb}$ tot] values were calculated.

\section{Data Analysis and Statistics}

For each infant, two 30-s periods were compared (Fig. 2). Period 1 (P1) consisted of a 30-s baseline duration before exposure to the smell. Period 2 (P2) included the exposure time $(10 \mathrm{~s})$ and the following $20 \mathrm{~s}$. The data registered by the NIRS apparatus were exported every second. Thus, each of the periods contained 30 numerical values corresponding to $[\mathrm{Hb}$ $\mathrm{O}_{2}$ ] and 30 values to $[\mathrm{Hb} \mathrm{H}]$. [Hb tot] was calculated off-line as $\left[\mathrm{Hb} \mathrm{O}_{2}\right]+[\mathrm{Hb} \mathrm{H}](27)$. For each baby, the mean value of the difference between P1 and P2 for $\left[\mathrm{Hb} \mathrm{O}_{2}\right]_{\text {diff }},[\mathrm{Hb} \mathrm{H}]_{\text {diff, }}$, and $[\mathrm{Hb} \text { tot }]_{\text {diff }}$ were calculated by subtracting $\mathrm{P} 1$ values from $\mathrm{P} 2$ values.

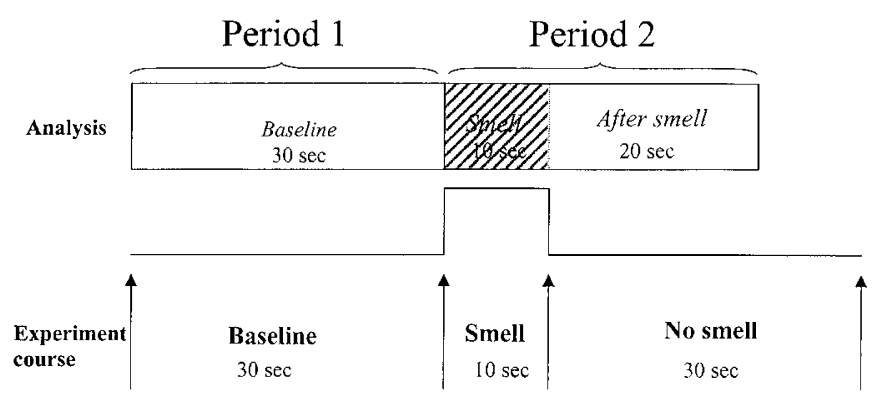

Figure 2. Different phases of the experiment course (bottom panel) and the corresponding periods that have been chosen for analysis (top panel). The 30-s baseline constitutes Period 1. The 10-s smell exposure time plus 20-s period immediately after the exposure comprise Period 2 . This experimental procedure was used when the baby was exposed both to Neomidil and Remove. 
For each second of registration, an averaged value was calculated from all 20 babies, both in the basal condition (P1) and after stimulus (P2). In such a way it was possible to derive average curves describing the hemodynamic changes in the left and right hemisphere during the basal condition as well as during and after the exposure. Also, an averaged curve with mean values of $[\mathrm{Hb}]_{\text {diff }}$ was calculated.

To compare exposure-related changes in the same hemisphere, the $\mathrm{P} 1$ and $\mathrm{P} 2$ average curves for $\left[\mathrm{Hb} \mathrm{O}_{2}\right],[\mathrm{Hb} \mathrm{H}]$, and [Hb tot] were compared for each. To compare the differences between the two hemispheres, P1- and P2-average curves were compared with the contralateral ones. These analyses were performed using a $t$ test for dependent samples. Before performing a $t$ test, both Levene's test and Brown-Forsythe's test were used to verify the equality of variances - a mandatory condition for $t$ test analysis.

To calculate the latency interval between the exposure and significant changes in $[\mathrm{Hb} \text { tot }]_{\text {diff }}$, a time series stepwise analysis was carried out for both sides. For each sampling point (every $1 \mathrm{~s}$ ) after the onset of odor exposure, the mean values obtained from the 20 babies were compared to determine the cutoff point at which the average curves became significantly different from the baseline.

To evaluate interhemispheric differences in the change in $\mathrm{Hb}$ concentration, a comparison of $[\mathrm{Hb}]_{\mathrm{diff}}$ on the left and right sides was made. This was performed by a $t$ test for independent variables.

Correlation matrices were used to measure the relationship between $[\mathrm{Hb}]_{\text {diff }}$ and GA, PN, and PC.

Statistics were completed using the program Statistica (version 1998, StatSoft, Tulsa, OK, U.S.A.). A $p$ value $<.05$ was considered statistically significant.

\section{RESULTS}

\section{Panel Judgment of Intensity and Hedonic Value}

The panel judged the intensity of the disinfectant to be significantly stronger than the smell of water and colostrum (ANOVA and Newman-Keuls posthoc comparison, $p<0.001$ for both), but similar in strength to that of vanilla. The panel also rated water and colostrum as neutral $(p<0.01$ versus Neomidil and Remove), and Neomidil and Remove as unpleasant and vanilla as pleasant (ANOVA and Newman-Keuls posthoc comparison, $p<0.001$ ) (Fig. 3).

\section{Newborns: Circulatory/Respiratory Responses to Olfactory Exposure}

$\mathrm{HR}, \mathrm{RR}$, and peripheral $\mathrm{SaO}_{2}$ did not change significantly during the P1 and P2 for either smell stimuli tested. No differences were noted between males and females.

\section{Newborns: NIRS Data in Response to Olfactory Exposure}

$\left[\mathrm{Hb}_{2} \mathrm{O}_{2}\right]$ and $[\mathrm{Hb}$ tot] changed almost in parallel during NIRS registrations as a result of the small changes in $[\mathrm{Hb} \mathrm{H}]$. Thus, we have primarily limited our report to $\left[\mathrm{Hb} \mathrm{O}_{2}\right]$ changes.

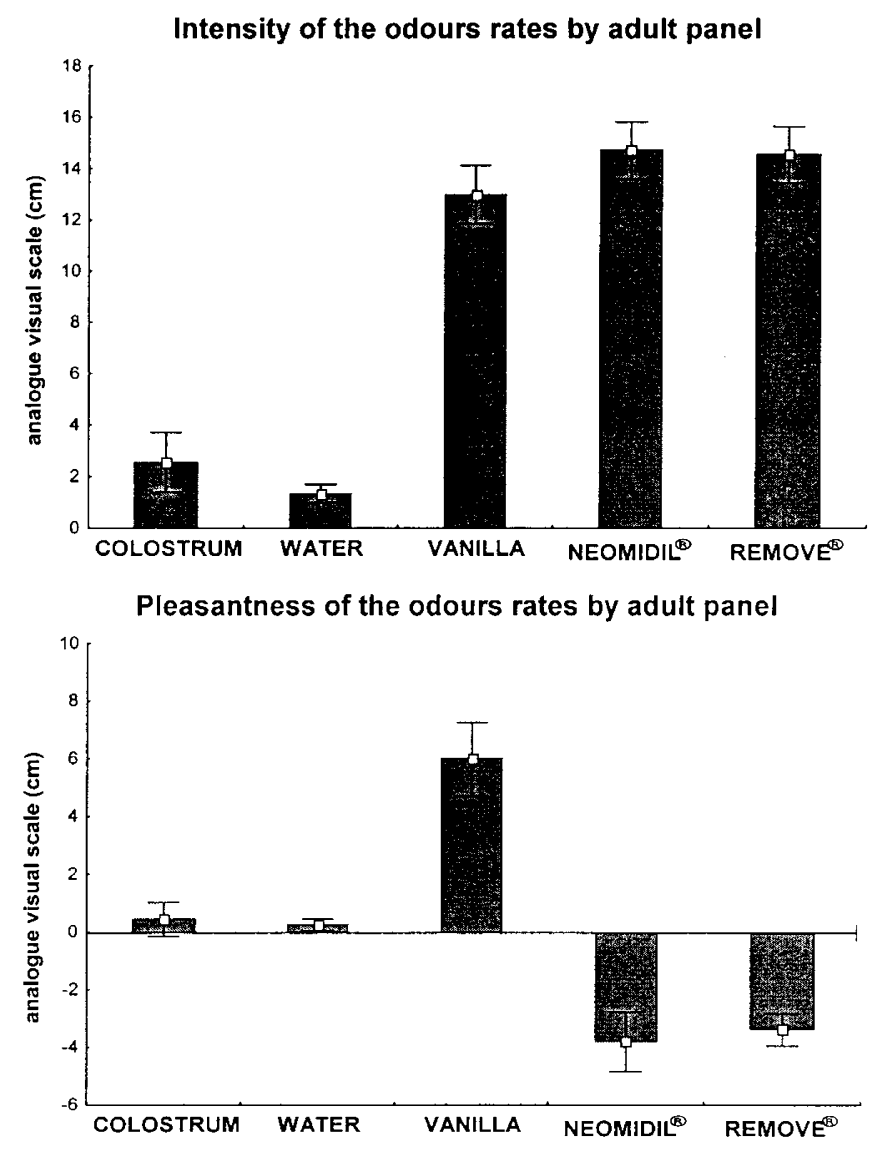

Figure 3. Adult panel judgment of the two tested substances and comparison with three control substances. Upper panel: Intensity score. Vanilla, Neomidil, and Remove were scored as significantly more intense then colostrum and water ( $p<0.001$ for all comparisons). Lower panel: Pleasantness value. Zero indicates neutral. Neomidil and Remove were scored as unpleasant by the panelists compared with vanilla $(p<0.001)$, colostrum $(p<0.01)$, and water $(p<0.01)$. Columns represent mean values and whiskers standard errors. Statistical analysis has been performed by using ANOVA and Newman-Keuls posthoc comparison.

Neomidil odor (15 cases). Before the exposure (P1), only minor fluctuations around the baseline of $\left[\mathrm{Hb} \mathrm{O}_{2}\right],[\mathrm{Hb} \mathrm{H}]$, and $[\mathrm{Hb}$ tot] were observed. There were no differences between left and right sides. After the exposure, 13 of 15 babies responded with a significant decrease in $\left[\mathrm{Hb} \mathrm{O}_{2}\right]$ and $[\mathrm{Hb}$ tot] in both sides $(p<0.0001)$. The changes of $[\mathrm{Hb} \mathrm{H}]$ were different: on the right side there was a nonsignificant increase compared with the baseline, whereas on the left side there was a significant decrease $(p<0.05)$. An example is shown in Figure 4 . The difference between left and right response was highly significant $\left([\mathrm{Hb} \mathrm{H}]_{\text {diff }}\right.$ left versus right, $\left.p<0.0001\right)$. A comparison between left and right sides showed a significantly larger decrease on the right side for both $\left[\mathrm{Hb} \mathrm{O}_{2}\right]_{\text {diff }}$ and $[\mathrm{Hb} \text { tot }]_{\text {diff }}(p$ $<0.01$ for $\left[\mathrm{Hb} \mathrm{O}_{2}\right]_{\text {diff }}$ and $p<0.05$ for $[\mathrm{Hb} \text { tot }]_{\text {diff, }}$, respectively) (Figs. 5). Additionally, older babies tended to exhibit a diminished $[\mathrm{Hb} \text { tot }]_{\text {diff }}$ in the right side $(r$ value $=0.44$, with $95 \%$ confidence interval).

The average curves for changes during exposure showed that the decrease in $\left[\mathrm{Hb} \mathrm{O}_{2}\right]_{\text {diff }}$ from the baseline started around $4 \mathrm{~s}$ after onset of exposure $(p<0.05)$ in the right side and around $6 \mathrm{~s}$ in the left side $(p<0.05)$ (Fig. 5). 

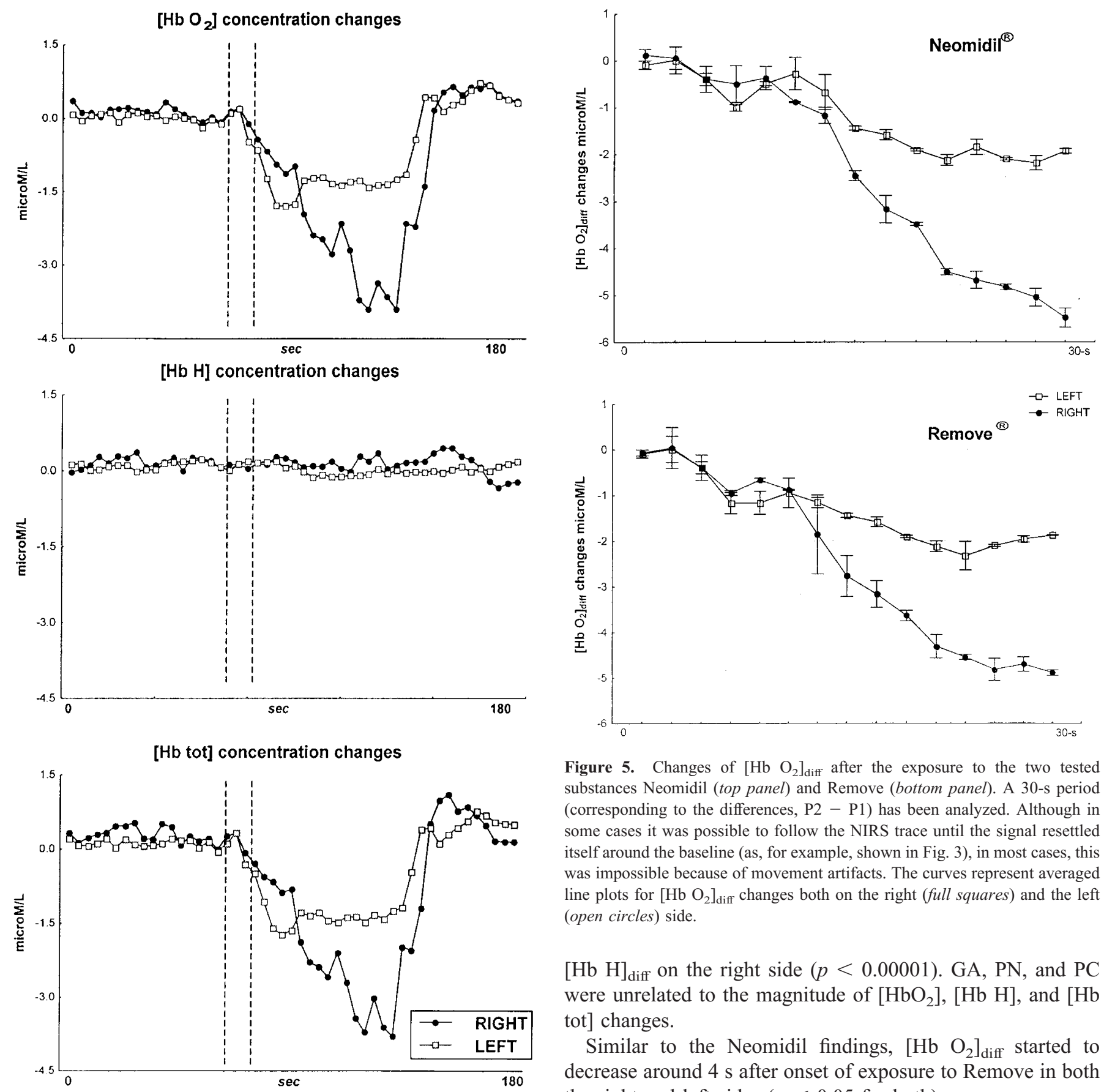

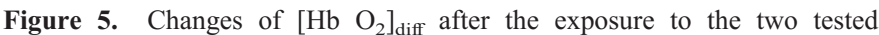
substances Neomidil (top panel) and Remove (bottom panel). A 30-s period (corresponding to the differences, P2 - P1) has been analyzed. Although in some cases it was possible to follow the NIRS trace until the signal resettled itself around the baseline (as, for example, shown in Fig. 3), in most cases, this was impossible because of movement artifacts. The curves represent averaged line plots for $\left[\mathrm{Hb} \mathrm{O}_{2}\right]_{\mathrm{diff}}$ changes both on the right (full squares) and the left (open circles) side.

$[\mathrm{Hb} \mathrm{H}]_{\mathrm{diff}}$ on the right side $(p<0.00001)$. GA, PN, and PC were unrelated to the magnitude of $\left[\mathrm{HbO}_{2}\right],[\mathrm{Hb} \mathrm{H}]$, and $[\mathrm{Hb}$ tot] changes.

Similar to the Neomidil findings, $\left[\mathrm{Hb} \mathrm{O}_{2}\right]_{\text {diff }}$ started to decrease around $4 \mathrm{~s}$ after onset of exposure to Remove in both the right and left sides ( $p<0.05$ for both).

Figure 4. Explicative case. Changes of $\left[\mathrm{Hb} \mathrm{O}_{2}\right]$ (top panel), $[\mathrm{Hb} \mathrm{H}]$ (middle panel), and [ $\mathrm{Hb}$ tot] (bottom panel) in one case after a 10-s exposure (dotted lines) to Neomidil. The decrease was more pronounced on the right side (solid circles) than on the left side (open squares). An analogous trace was seen after exposure to Remove. [ $\mathrm{Hb}$ tot] changes paralleled those of $\left[\mathrm{Hb} \mathrm{O}_{2}\right]$.

Remove odor (5 cases). The baseline did not show any major changes in any of the NIRS variables, and left and right recordings were not significantly different. After exposure to Remove, four out of five babies responded with a decrease in $\left[\mathrm{Hb} \mathrm{O}_{2}\right]$ and $[\mathrm{Hb}$ tot], especially in the right hemisphere $(p<$ 0.01 ) (Fig. 5). $[\mathrm{Hb} \mathrm{H}]$ decreased slightly on the left side (not statistically significant), whereas an increase was recorded on the right side. When comparing the $[\mathrm{Hb} \mathrm{H}]$ differences between pre- and postexposure, there was a significantly higher value of

\section{DISCUSSION}

Newborn infants, especially in the NICU, are exposed to a range of artificial, unnatural olfactory stimuli. We have little, if any, idea of how such stimuli influence their brain function, activating neuronal circuits. Therefore, in our study, premature babies in controlled conditions were exposed to the smell of two commercially available solutions commonly used in the NICU (i.e. a disinfectant and an adhesive remover). The smell of both solutions was judged by an adult panel to be both strong and unpleasant.

The main finding of this study was that the odors of these two solutions elicited a decrease in blood oxygenation in an area likely to include the orbitofrontal olfactory area. This 
change was different from that caused by exposure to colostrum and vanilla, which elicited an increase in blood oxygenation in the same region (9).

It has been assumed that neuronal firing per se (rather than cerebral metabolism alone) not only consumes oxygen, but also regulates r-CBF (28). Most functional studies using NIRS have therefore been based on the assumption that cortical activation is coupled with an increase in local cerebral blood volume, which is registered as an increase in $\left[\mathrm{Hb} \mathrm{O}_{2}\right]$ and $[\mathrm{Hb}$ tot]. However, the $\mathrm{Hb}$ changes recorded by NIRS, after a certain stimulus, have been differently described. It has been shown that physiologic aging can influence $\mathrm{Hb}$ oxygenation in response to brain activation, as the increase in $\left[\mathrm{Hb} \mathrm{O}_{2}\right]$ and $[\mathrm{Hb}$ tot] is less pronounced in elderly men (29). Moreover, Hoshi (30) described a decrease in $\left[\mathrm{Hb} \mathrm{O}_{2}\right]$ in response to mental tasks. In addition, cortical activity was seen to be associated with a decrease in $\left[\mathrm{Hb} \mathrm{O}_{2}\right]$ and $[\mathrm{Hb} \mathrm{H}]$ levels in particular pathologic conditions, such as Alzheimer's disease (31). To reconcile these conflicting findings, it has been suggested that an increase in $\left[\mathrm{Hb} \mathrm{O}_{2}\right]$ and $[\mathrm{Hb}$ tot] is seen when $\mathrm{r}-\mathrm{CBF}$ exceeds oxygen consumption, whereas a decrease in $\left[\mathrm{Hb} \mathrm{O}_{2}\right]$ and $[\mathrm{Hb}$ tot] occurs when the increased oxygen demand is not counterbalanced by an increased $\mathrm{CBF}$ in the illuminated area (14).

When interpreting the present data, it is also important to consider that unpleasant odorants can lead to cortical deactivation (32). Fransson et al. (33) recently investigated the correlation between deactivation and cerebral hemodynamics by magnetic resonance imaging, and they concluded that a state of cortical deactivation is associated with a decreased magnetic resonance signal, indicating a decrease in blood supply. Using the NIRS technique, a decrease in [Hb tot] has been defined as deactivation $(13,15,34)$. If our data are analyzed according to this definition, the recorded decrease in $\left[\mathrm{Hb} \mathrm{O}_{2}\right]$ and $[\mathrm{Hb}$ tot] might indicate a cortical deactivation related to the likely unpleasant olfactory stimulation. This finding would be supported by the $[\mathrm{Hb} \mathrm{H}]$ increase on the right side, but not on the left where a $[\mathrm{Hb} \mathrm{H}]$ decrease was observed. On neither side did the $[\mathrm{Hb} \mathrm{H}]$ changes affect $[\mathrm{Hb}$ tot $]$ concentration significantly.

In a recent study, Soussignan et al. (35) analyzed the neonate's olfacto-facial expression during different olfactory stimulations and concluded that behavioral markers of disgust (nose-wrinkling, upper lip-raising) discriminated some odors judged by adults to be pleasant with those judged to be unpleasant (e.g. vanillin versus butyric acid). However, despite some early similarity in processing olfactory stimuli's affective significance, there is no definitive evidence that newborns can discriminate between the hedonic valence of odors within the same perceptual range as adults.

In general, pleasant odors elicit approach behavior whereas unpleasant odors induce avoidance behavior. In both our first work (9) and the present work, we observed the newborn's behavioral reactions during exposure to the smells - although our observations were neither systematic nor quantitative. The general facial response of the newborns when exposed to the smell of the remover or the disinfectant consisted of an initial flaring of the nostril followed by nose-wrinkling, brow- lowering, upper eyelid-lowering, and tendency to avoid the source of the smell by small head movements.

Substances containing different odorous compounds may have multiple targets in the brain cortex, including olfactory areas, olfactory-related areas, and other unrelated regions. Some compounds present in the fluids we tested, such as acetone, camphor, alcohol, and ether, may activate the trigeminal subsystem that seems to be fully receptive at $22 \mathrm{wk}$ of gestation. Trigeminal subsystem contribution to the modulation of cerebral hemodynamics can be both indirect and direct. Parasympathetic projections arising from the sphenopalatine ganglion, which itself is innervated by trigeminal fibers (36), distribute through the ethmoid nerve to the cerebral vessels $(37,38)$. A considerable number of sensory trigeminal projections directly innervate cerebral blood vessels as collaterals from the same fibers that innervate the nasal cavity $(39-41)$. These fibers project to second-order neurons in the trigeminal nucleus caudalis and its caudal extension into $\mathrm{C} 1$ and $\mathrm{C} 2$ cervical spinal cord (42). A trigemino-vascular system activation may play a major role in the response we observed by causing a redistribution of cerebral blood flow to certain areas of the brain, such as in the brain stem and upper cervical spinal cord, or the superior sagittal sinus. This may determine a $[\mathrm{Hb}$ $\mathrm{O}_{2}$ ] and [ $\mathrm{Hb}$ tot] decrease in the region that we have illuminated. The controversial results that we observed in $[\mathrm{Hb} \mathrm{H}]$ changes may be related to differences in blood supply to those regions activated and deactivated by the different compounds.

Repetitive exposures to the same odor may affect the olfactory processing mechanisms (43) in both adults and newborn $(44,45)$. Thus, the number of times that each subject was exposed to Neomidil, Remove, or other substances containing analogous compounds might be an interesting factor to consider in further studies. In fact, newborns in NICU may be exposed to the smell of these substances several times a day. Although a systematic videotaping and analysis of the newborn's behavioral reaction was not performed, a common facial response as described above was been observed in the whole population irrespective of whether or not the infant had been exposed to the substance before.

The penetration depth of near-infrared light is higher in newborns than in adults. There is reason to believe that in the subjects we have studied the illuminated region included the more superficial cortex as well as deeper areas such as the amygdaloid cortex. This part of the brain-especially on the right side - seems to be involved in the perception of unpleasant smells (46). Interestingly, in our study, the right side exhibited a stronger response than the left in processing likely unpleasant odors.

Our findings have shown that a cortical response is elicited by exposure to odors that preterm infants often encounter in the NICU environment. They also have confirmed the ability of NIRS to explore functional activation of the brain cortex in the newborn. These hemodynamic changes are likely the result of a dynamic, physiologic regulation of $\mathrm{r}-\mathrm{CBF}$ based upon the olfactory- and trigeminus-related areas of the brain. The dramatic functional response after exposure to common smells in an NICU underlines the sensibility and competence of the olfactory system in premature babies. The biologic significance 
of exposure to unpleasant odors is unknown, but with regard to the close connections between olfactory cortex and centers regulating emotional state, it might be worth considering. This raises the question as to whether or not and to what degree certain smelling substances should be used in the NICU. Further investigations are needed to understand whether exposure to artificial, unpleasant odors can affect brain development and capacity to process smells.

Acknowledgments. We thank the nurses in both NICUs in Genoa and Stockholm, whose generous help made this study possible. We also thank Annika Olsson for her valuable help in reviewing the manuscript.

\section{REFERENCES}

1. Gottfried AW, Wallace-Lande P, Sherman-Brown S, King J, Coen C, Hodgman JE 1981 Physical and social environment of newborn infants in special care units. Science 214:673-675

2. Linn PL, Horowitz FD, Fox HA 1985 Stimulation in the NICU: is more necessarily better? Clin Perinatol 12:407-422

3. Anderson J 1986 Sensory intervention with the preterm infant in the neonatal intensive care unit. Am J Occup Ther 40:19-26

4. Blackburn S 1998 Environmental impact of the NICU on developmental outcomes. J Pediatr Nurs 13:279-289

5. White-Traut RC, Nelson MN, Silvestri JM, Patel M, Vasan U, Han BK, Cunningham N, Burns K, Kopischke K, Bradford L 1999 Developmental intervention for preterm infants diagnosed with periventricular leukomalacia. Res Nurs Health 22:131-143

6. Meek JH, Firbank M, Elwell CE, Atkinson J, Braddick O, Wyatt JS 1998 Regional hemodynamic responses to visual stimulation in awake infants. Pediatr Res 43:840843

7. Sakatani K, Chen S, Lichty W, Zuo H, Wang YP 1999 Cerebral blood oxygenation changes induced by auditory stimulation in newborn infants measured by near infrared spectroscopy. Early Hum Dev 55:229-236

8. Zaramella P, Freato F, Amigoni A, Salvadori S, Marangoni P, Suppjei A, Schiavo B, Chiandetti L 2001 Brain Auditory Activation Measured by Near-Infrared Spectroscopy (NIRS) in Neonates Pediatr Res 49:213-219

9. Bartocci M, Winberg J, Ruggiero C, Bergqvist L, Serra G, Lagercrantz H 2000 Activation of olfactory cortex in newborn infants after odour stimulation. Pediatr Res $48: 18-23$

10. Sarnat HB 1978 Olfactory reflexes in the newborn infant. J Pediatr 92:624-626

11. Kleinschmidt A, Obrig H, Requardt M, Merboldt KD, Dirnagl U, Villringer A, Frahm J 1996 Simultaneous recording of cerebral blood oxygenation changes during human brain activation by magnetic resonance imaging and near-infrared spectroscopy. J Cereb Blood Flow Metab 16:817-826

12. Villringer A, Planck J, Stodieck S, Botzel K, Schleinkofer L, Dirnagl U 1994 Noninvasive assessment of cerebral hemodynamics and tissue oxygenation during activation of brain cell function in human adults using near infrared spectroscopy. In: Vaupel P (ed) Oxygen Transport to Tissue. Plenum Press, New York, pp 559-565

13. Obrig H, Villringer A 1997 Near-infrared spectroscopy in functional activation studies. Can NIRS demonstrate cortical activation? Adv Exp Med Biol 413:113-127

14. Villringer A, Chance B 1997 Non-invasive optical spectroscopy and imaging of human brain function. Trends Neurosci 20:435-42

15. Benaron DA, Hintz SR, Villringer A, Boas D, Kleinschmidt A, Frahm J, Hirth C, Obrig H, van Houten JC, Kermit EL, Cheong WF, Stevenson DK 2000 Noninvasive functional imaging of human brain using light. J Cereb Blood Flow Metab 20:469477

16. Kato T, Kamei A, Takashima S, Ozaki T 1993 Human visual cortical function during photic stimulation monitoring by means of near-infrared spectroscopy. J Cereb Blood Flow Metab 13:516-520

17. Villringer A, Planck J, Hock C, Schleinkofer L, Dirnagl U 1993 Near infrared spectroscopy (NIRS): a new tool to study hemodynamic changes during activation of brain function in human adults. Neurosci Lett 154:101-104

18. Okada F, Tokumitsu Y, Hoshi Y, Tamura M 1994 Impaired interhemispheric integration in brain oxygenation and hemodynamics in schizophrenia. Eur Arch Psychiatry Clin Neurosci 244:17-25

19. Meek JH, Elwell CE, Khan MJ, Romaya J, Wyatt JS, Delpy DT, Zeki S 1995 Regional changes in cerebral haemodynamics as a result of a visual stimulus measured by near infrared spectroscopy. Proc R Soc Lond B Biol Sci 261:351-356

20. Prechtl HF 1974 The behavioural states of the newborn infant (a review). Brain Res 76:185-212
21. Jöbsis FF 1977 Noninvasive, infrared monitoring of cerebral and myocardial oxygen sufficiency and circulatory parameters. Science 198:1264-1267

22. Edwards AD, Wyatt JS, Richardson C, Delpy DT, Cope M, Reynolds EO 1988 Cotside measurement of cerebral blood flow in ill newborn infants by near infrared spectroscopy. Lancet 2:770-771

23. Cope M, Delpy DT 1988 System for long-term measurement of cerebral blood and tissue oxygenation on newborn infants by near infra-red transillumination. Med Biol Eng Comput 26:289-294

24. Cope M, Delpy DT, Reynolds EO, Wray S, Wyatt J, van der Zee P 1988 Methods of quantitating cerebral near infrared spectroscopy data. Adv Exp Med Biol 222:183189

25. Matcher SJ, Cope M, Delpy DT 1994 Use of the water absorption spectrum to quantify tissue chromophore concentration changes in near-infrared spectroscopy. Phys Med Biol 39:177-196

26. Wyatt JS, Cope M, Delpy DT, Richardson CE, Edwards AD, Wray S, Reynolds EO 1990 Quantitation of cerebral blood volume in human infants by near-infrared spectroscopy. J Appl Physiol 68:1086-1091

27. Wyatt JS, Cope M, Delpy DT, Wray S, Reynolds EO 1986 Quantification of cerebral oxygenation and haemodynamics in sick newborn infants by near infrared spectrophotometry. Lancet 2:1063-1066

28. Fox PT, Raichle ME 1986 Focal physiological uncoupling of cerebral blood flow and oxidative metabolism during somatosensory stimulation in human subjects. Proc Natl Acad Sci U S A 83:1140-4

29. Hock C, Muller-Spahn F, Schuh-Hofer S, Hofmann M, Dirnagl U, Villringer A 1995 Age dependency of changes in cerebral hemoglobin oxygenation during brain activation: a near-infrared spectroscopy study. J Cereb Blood Flow Metab 15:1103-1108

30. Hoshi Y, Onoe H, Watanabe Y, Andersson J, Bergstrom M, Lilja A, Langstrom B, Tamura M 1994 Non-synchronous behavior of neuronal activity, oxidative metabolism and blood supply during mental tasks in man. Neurosci Lett 172:129-133

31. Hock C, Villringer K, Müller-Spahn F, Wenzel R, Heekeren H, Schuh-Hofer S, Hofmann M, Minoshima S, Schwaiger M, Dirnagl U, Villringer A 1997 Decrease in parietal cerebral hemoglobin oxygenation during performance of a verbal fluency task in patients with Alzheimer's disease monitored by means of near-infrared spectroscopy (NIRS) - correlation with simultaneous rCBF-PET measurements. Brain Res 755:293-303

32. Brauchli P, Ruegg PB, Etzweiler F, Zeier H 1995 Electrocortical and autonomic alteration by administration of a pleasant and an unpleasant odor. Chem Senses 20:505-515

33. Fransson P, Kruger G, Merboldt KD, Frahm J 1999 MRI of functional deactivation: temporal and spatial characteristics of oxygenation-sensitive responses in human visual cortex. Neuroimage 9:611-618

34. Obrig H, Wenzel R, Kohl M, Horst S, Wobst P, Steinbrink J, Thomas F, Villringer A 2000 Near-infrared spectroscopy: does it function in functional activation studies of the adult brain? Int J Psychophysiol 35:125-142

35. Soussignan R, Schaal B, Marlier L, Jiang T 1997 Facial and autonomic responses to biological and artificial olfactory stimuli in human neonates: re-examining early hedonic discrimination of odors. Physiol Behav 62:745-758

36. Suzuki N, Hardebo JE, Owman C 1989 Trigeminal fibre collaterals storing substance $\mathrm{P}$ and calcitonin gene- related peptide associate with ganglion cells containing choline acetyltransferase and vasoactive intestinal polypeptide in the sphenopalatine ganglion of the rat. An axon reflex modulating parasympathetic ganglionic activity? Neuroscience 30:595-604

37. Walters BB, Gillespie SA, Moskowitz MA 1986 Cerebrovascular projections from the sphenopalatine and otic ganglia to the middle cerebral artery of the cat. Stroke $17: 488-494$

38. Suzuki N, Hardebo JE, Owman C 1988 Origins and pathways of cerebrovascular vasoactive intestinal polypeptide-positive nerves in rat. J Cereb Blood Flow Metab 8:697-712

39. Finger TE, Böttger B 1993 Peripheral peptidergic fibers of the trigeminal nerve in the olfactory bulb of the rat. J Comp Neurol 334:117-124

40. Fusco BM, Fiore G, Gallo F, Martelletti P, Giacovazzo M 1994 "Capsaicin-sensitive" sensory neurons in cluster headache: pathophysiological aspects and therapeutic indication. Headache 34:132-137

41. Major DA, Silver WL 1999 Odorants presented to the rat nasal cavity increase cortical blood flow. Chem Senses 24:665-669

42. Kaube H, Keay KA, Hoskin KL, Bandler R, Goadsby PJ 1993 Expression of c-Fos-like immunoreactivity in the caudal medulla and upper cervical spinal cord following stimulation of the superior sagittal sinus in the cat. Brain Res 629:95-102

43. Distel H, Ayabe-Kanamura S, Martinez-Gomez M, Schicker I, Kobayakawa T, Saito S, Hudson R 1999 Perception of everyday odors-correlation between intensity, familiarity and strength of hedonic judgement. Chem Senses 24:191-199

44. Sullivan RM, Taborsky-Barba S, Mendoza R, Itano A, Leon M, Cotman CW, Payne TF, Lott I 1991 Olfactory classical conditioning in neonates. Pediatrics 87:511-518

45. Varendi H, Porter RH, Winberg J 1997 Natural odour preferences of newborn infants change over time. Acta Paediatr 86:985-990

46. Zald DH, Pardo JV 1997 Emotion, olfaction, and the human amygdala: amygdala activation during aversive olfactory stimulation. Proc Natl Acad Sci U S A 94:41194124 